Euाrope-

Addiction

Research
Alcohol

Eur Addict Res 2003;9:45-50

DOI: $10.1159 / 000067733$

\title{
Alcohol Consumption in Heroin Users, Methadone-Substituted and Codeine-Substituted Patients - Frequency and Correlates of Use
}

\author{
Markus Backmund ${ }^{a}$ Christian G. Schüt ${ }^{b}$ Kirsten Meyera \\ Dieter Eichenlauba Michael Soykab \\ ${ }^{a}$ Addiction Medicine, General Hospital Munich-Schwabing, and ${ }^{\mathrm{b}}$ Department of Psychiatry, University of Munich, \\ Germany
}

\section{Key Words}

Co-abuse · Alcohol · Methadone - Dihydrocodeine • Heroin

\begin{abstract}
This retrospective study aims to determine whether there is a difference in the additional consumption of alcohol between addicts treated with methadone or dihydrocodeine $(\mathrm{DHC})$ and untreated addicts injecting heroin. 1,685 patients admitted for opioid withdrawal between 1991 and 1997 were reviewed. Cross-reference tables and multiple logistic regression analyses were carried out. $28 \%$ of patients take more than $40 \mathrm{~g}$ of alcohol daily (on average $176 \mathrm{~g}$ ). We found that patients who are treated with methadone or DHC drink alcohol significantly more often daily than the heroin-dependent patients $(p<0.01)$. Using multiple regression analyses, the results were confirmed. Additionally, we found that co-abuse of alcohol was predicted by male gender, longer duration of drug use, additional daily consumption of tetrahydrocannabinol and daily consumption of benzodiazepines. Alcohol consumption by opioid-addicted patients treated with methadone or DHC presents a serious medical problem. Co-abuse of alcohol will receive more attention.
\end{abstract}

Copyright @2003S. Karger AG, Basel

\section{Introduction}

Consumption of other psychotropic substances during substitution treatment of opioid addicts with methadone and dihydrocodeine (DHC) may have a substantial impact on morbidity, mortality and clinical course. While consumption of illegal drugs is usually reduced during substitution treatment, additional consumption of legal psychotropic substances, especially of alcohol, has not been examined in such detail. Chronic alcohol consumption leads to a variety of somatic effects and diseases. Therefore, where a high prevalence of regular or severe alcohol consumption exists among patients in substitution programs, the advantages and risks should be carefully weighed up. Further, to the consumption of respirantdepressive opioids, additional complications and dangers are involved when taking other psychotropic substances with respiration-depressive effects, such as alcohol, benzodiazepines or barbiturates. $62-72 \%$ of the patients, who had been treated for overdosing, had consumed various substances [1, 2], of which 23-35\% comprised alcohol. In cases of fatal overdosing, abuse with multiple substances was reported in $71-92 \%$ of patients [3-7]. In $41-51 \%$ of these deaths, alcohol was identified. In addition to the acute risk of an overdose from combined consumption of a number of psychotropic substances, the consumption of

\footnotetext{
Markus Backmund, MD

Krankenhaus München-Schwabing

Kölner Platz 1

D-80804 München (Germany)

Tel. +49 89 30683366, Fax +49 89 30683934, E-Mail Markus.Backmund@kms.mhn.de
} 
alcohol, in contrast to opioids, leads to chronic permanent damage and disease concerning almost all aspects of medicine [8-11].

On the one hand, a number of studies have ascertained that the supplementary consumption of illegal drugs such as heroin and cocaine may be reduced by methadone maintenance treatment programs [12-15] and codeine maintenance programs [16]. On the other hand, it has often been reported that about $30 \%$ of the patients in methadone maintenance treatment programs have an alcohol problem or are even alcoholics [17-19]. It is not clear, however, whether the patients already had alcohol problems before their entry into the methadone maintenance treatment. The North Rhine Westphalia study on the efficacy of outpatient medical rehabilitation with methadone maintenance indicated that over time the number of patients being abstinent of alcohol increased during treatment [20].

In Germany, the critical dose is often stated as $60 \mathrm{~g}$ for men and $40 \mathrm{~g}$ for women [21]. More than 8,000 deaths of people aged 15-29 years in Europe in 1999 were attributable to alcohol [22].

In addition to the risk of overdosing, alcoholism for example leads to an increased risk of long-term secondary physical sicknesses $[8,9]$. With regard to narcotics fatalities, toxicological data from southern Bavaria - the same area as in our study - indicate that alcohol is a frequent covariant in drug-related deaths and in patients treated with codeine $(27 \%$ each) and that it is less frequent in methadone patients (16\%) [23].

Those studies concerned with supplementary consumption within methadone and codeine maintenance treatment programs have mainly focused on the supplementary consumption of illegal drugs. We further consider that in Germany, and especially Bavaria, where alcohol is everywhere easily available and where alcohol consumption is well established (e.g. the 'Oktoberfest'), heroin addicts consider alcohol consumption analogous to a 'normal' individual's regular consumption of alcohol, and more so when heroin becomes more difficult to obtain. We thus present our hypothesis that those patients treated with methadone or DHC drink less alcohol than the untreated patients injecting illegal heroin.

\section{Subjects and Methods}

Sample

All drug-addicted patients voluntarily admitted to inpatient detoxification treatment between April 1991 and December 1996, in whom, according to ICD-10 criteria, an opioid or multiple-substance addiction had been diagnosed, were included in the study. Of all patients enrolled in the treatment program between April 1991 and December 1996, those subjects coming for a second or third detoxification visit within this time period had to be excluded, except for the first visit, otherwise the assumption of independent observations would have been violated. Patients could come in of their own volition, and previous contact with a counsellor or physician was not necessary. The treatment strategy called 'qualified detoxification' has been described elsewhere [24].

\section{Measures}

On the day of admission, the daily intake of psychotropic substances over the preceding 6 months was established. The patients were questioned individually regarding their intake of opioids, especially heroin, codeine/DHC and methadone $(D, L$-methadone, levomethadone), and of other psychotropic substances such as nicotine, benzodiazepines, barbiturates, cocaine, cannabis, amphetamines/amphetamine derivatives and alcohol. The alcohol intake was noted in grams of alcohol per day. $500 \mathrm{ml}$ beer was calculated as $20 \mathrm{~g}$ alcohol, $500 \mathrm{ml}$ cognac (40\%) or vodka (40\%) as $160 \mathrm{~g}$ alcohol [21]. The declarations were verified by an immunoassay urine test $\left(\right.$ Triage $^{\circledR}$ ) and a KIMS test (kinetic interaction of microparticles in a solution).

The patients were divided into 3 groups according to the preferred opioid of each individual. Those who daily received methadone or levomethadone (summarized as methadone) were included in group 1, those who took codeine or DHC daily (summarized as DHC) in group 2 and those daily consuming heroin in group 3. If primarily two opioids were taken daily, then the priority sequence of heroin before methadone before DHC was decisive. If none of the opioids were taken daily, but rather several of them alternatively, then these patients were not introduced into any of the 3 groups. Data concerning the daily intake of other psychotropic substances were collected for each group, as well as the gender of the patient, duration of addiction, age at first opioid use, age, marital status, history of imprisonment, history of suicide attempts and employment. Alcohol was separated and selected as a dependent variable (co-abuse of alcohol). Co-abuse of alcohol was defined as consumption of more than $40 \mathrm{~g}$ alcohol per day. The 40 -gram value was chosen since it is the stated critical dose of alcohol per day in most other published reports $[21,22,25,26]$.

\section{Statistics}

After cross-tabulation and bivariate analysis, a logistic regression model was established. Bivariate analyses were performed for the variable of interest and all further potentially relevant variables. Since preliminary analysis indicated nonlinear associations involving type of opioid dependency, age, duration of drug use, age at first opioid use, marital status and history of imprisonment, these variables were transformed from ordinal to categorical variables. Results are summarized by reporting a 'full model' that includes all investigated variables regardless of their statistical significance. Tests for interactions were used as a check on the uniformity assumption under which multiple regression estimates are derived.
46

Eur Addict Res 2003;9:45-50
Backmund/Schütz/Meyer/Eichenlaub/ Soyka 


\section{Results}

During the observation period from April 1991 to December 1996, 1,656 patients were voluntarily admitted to stationary qualified withdrawal treatment, $36 \%$ women and $64 \%$ men. 537 of these were patients readmitted within the given time frame. Of these patients only the first admission was included in the study in order not to violate the assumption of independent observations. 49 patients were not included since they had daily consumed several different opioids. 137 patients, $36 \%$ women and $64 \%$ men, who daily received methadone, were included in group 1.658 patients, $34 \%$ women and $66 \%$ men, due to their daily intake of codeine/DHC were placed into group 2.275 patients, $39 \%$ women and $61 \%$ men, daily consuming heroin formed group 3 . The average age was 30.7 years in group 1, 28.9 years in group 2 and 28.3 years in group 3. The average duration of addiction to opioids was substantiated as 10.5 years in group $1,8.9$ years in group 2 and 8.2 years in group 3 .

301 patients consumed more than $40 \mathrm{~g}$ alcohol per day. These were evaluated as positive for the dependent variable 'co-abuse of alcohol'. On average, alcohol consumption was $176 \mathrm{~g} /$ day (table 1 ).

Contrary to our hypothesis, the bivariate analysis indicated that patients who are in a methadone or DHC maintenance treatment program daily drink alcohol significantly more often than the heroin-dependent patients $(\mathrm{p}<$ 0.01). Fewer patients who were treated with DHC (31.3\%) drink alcohol than patients who were treated with methadone (36.5\%). Table 2 presents bivariate analyses on the key variable and possible confounding variables predicting co-abuse of alcohol. As shown, co-abuse of alcohol was predicted by male gender, older age, longer duration of drug use, additional daily consumption of tetrahydrocannabinol (THC), daily consumption of barbiturates and daily consumption of benzodiazepines.

Table 3 shows the results of a multiple logistic regression analysis. The key finding that patients consuming heroin drink less alcohol than patients who were treated with DHC or methadone persists even when all investigated variables regardless of their statistical significance were included in the model. Age and daily consumption of barbiturates turned out not to be a significant predictor of co-abuse of alcohol. None of the other previously entered significant variables like gender (odds ratio, OR, $0.61,95 \%$ confidence interval, $\mathrm{CI}, 0.44-0.84, \mathrm{p}<0.01$ ), duration of drug use (OR $0.19,95 \%$ CI $0.05-0.74, \mathrm{p}<$ 0.05 ), daily consumption of benzodiazepines (OR 0.52 , $95 \%$ CI $0.38-0.71, \mathrm{p}<0.001)$ and daily consumption of
Table 1. Consumption of alcohol by opioid patients consuming more than $40 \mathrm{~g}$ of alcohol per day (defining 'co-abuse of alcohol')

\begin{tabular}{ll}
\hline $\begin{array}{l}\text { Quantity of alcohol } \\
\text { g/day }\end{array}$ & $\begin{array}{l}\text { Patients }(\mathrm{n}=301) \\
\%\end{array}$ \\
\hline $40-60$ & 12.0 \\
$61-120$ & 23.9 \\
$121-180$ & 27.2 \\
$181-240$ & 13.3 \\
More than 240 & 23.6 \\
Total & 100 \\
\hline
\end{tabular}

THC (OR 0.67, 95\% CI 0.47-0.95, p < 0.05) became insignificant, even though our variable of interest 'type of opioid dependency' remained only marginally significant (OR 2.38, 95\% CI 1.42-4.00, p < 0.001; table 3).

\section{Discussion}

The aim of this study was to investigate the association between the consumption of alcohol and the daily preferred opioid (methadone, DHC or heroin). The results indicate that patients consuming heroin drink less alcohol on a regular basis. In comparison to the patients who consume DHC, patients in a methadone maintenance program drink alcohol more often $(36.5 \%$ of the methadone patients vs. $31.3 \%$ of the DHC patients). The hypothesis had therefore to be rejected. One explanation might be due to the effect of the substance, i.e. that heroin is the one substance with which the desired effect according to the addicts may best be attained. Other opioids such as methadone and DHC do not completely produce the desired effect so that other additional substances, e.g. alcohol, are consumed. In published reports, problematic alcohol consumption by opiate users is given as varying between $12 \%$ [27], $32 \%[18,28]$ and $42 \%$ [27]. In this spectrum, the individual subgroups of our study are found, with $16 \%$ problem drinkers in the heroin group, $31.3 \%$ in the codeine group and $36.5 \%$ in the methadone group. It is becoming increasingly possible in Europe to use various opioids as substitutes. This is understandable when one considers the high mortality rate of drug addicts, which, in a meta-analysis, was found to be more than 13 times greater than in the average populations' equivalent age group [29]. Researchers and practitioners are therefore required to re-evaluate indication positions and to annotate advantages and disadvantages of each substance. An 
Table 2. Cross-tabulation and bivariate analyses for the primary variables of interest and secondary potentially relevant variables

\begin{tabular}{|c|c|c|c|c|c|}
\hline \multirow[t]{2}{*}{ Variable } & \multicolumn{5}{|c|}{ Co-abuse of alcohol (more than $40 \mathrm{~g}$ alcohol per day) } \\
\hline & $\mathrm{n}$ & $\%$ & OR & $95 \%$ CI & $\mathrm{p}$ \\
\hline \multicolumn{5}{|c|}{ Type of opioid dependency } & 0.0000 \\
\hline Methadone & 137 & 36.5 & 3.02 & $1.88-4.85$ & 0.0000 \\
\hline DHC & 658 & 31.3 & 2.39 & $1.67-3.44$ & 0.0000 \\
\hline Heroin & 275 & 16.0 & 1 & & \\
\hline \multicolumn{6}{|l|}{ Sex } \\
\hline Female & 377 & 21.2 & 0.58 & $0.43-0.78$ & 0.0003 \\
\hline Male & 693 & 31.7 & 1 & & \\
\hline \multicolumn{5}{|l|}{ Age } & 0.0081 \\
\hline$<23$ years & 217 & 21.7 & 0.58 & $0.37-0.91$ & 0.0169 \\
\hline $24-28$ years & 340 & 24.7 & 0.69 & $0.46-1.02$ & 0.0639 \\
\hline $29-34$ years & 324 & 33.0 & 1.04 & $0.70-1.52$ & 0.0851 \\
\hline$>34$ years & 186 & 32.3 & 1 & & \\
\hline \multicolumn{5}{|c|}{ Duration of opioid use } & 0.0000 \\
\hline$<1$ year & 79 & 06.3 & 0.14 & $0.64-1.96$ & 0.0001 \\
\hline $2-5$ years & 392 & 24.0 & 0.66 & $0.62-1.28$ & 0.0316 \\
\hline $6-10$ years & 251 & 30.3 & 0.90 & $0.66-1.47$ & 0.6277 \\
\hline $11-15$ years & 160 & 40.0 & 1.39 & $0.68-1.65$ & 0.1438 \\
\hline$>15$ years & 188 & 32.4 & 1 & & \\
\hline \multicolumn{6}{|c|}{ Daily consumption of THC } \\
\hline No & 873 & 26.3 & 0.65 & $0.47-0.90$ & 0.0100 \\
\hline Yes & 197 & 35.5 & 1 & & \\
\hline \multicolumn{6}{|c|}{ Daily consumption of barbiturates } \\
\hline No & 995 & 27.2 & 0.59 & $0.37-0.97$ & 0.0352 \\
\hline Yes & 75 & 38.7 & 1 & & \\
\hline \multicolumn{6}{|c|}{ Daily consumption of benzodiazepines } \\
\hline No & 597 & 20.9 & 0.45 & $0.34-0.59$ & 0.0000 \\
\hline Yes & 473 & 37.0 & 1 & & \\
\hline
\end{tabular}

The variables 'age at first opioid use', 'marital status', 'history of imprisonment', 'history of emergency treatment', 'history of suicide attempts', 'employment' and 'daily consumption of cocaine' were not significant.

$\mathrm{OR}=$ Odds ratio $; 95 \% \mathrm{CI}=95 \%$ confidence interval $; \mathrm{THC}=$ tetrahydrocannabinol. important target criterion should be the parallel consumption of further psychotropic substances, especially alcohol. It is known that alcohol has a toxic effect on all organic systems and that therefore chronic consumption of alcohol causes many severe illnesses. If the patients now begin to drink alcohol during the methadone or DHC substitution treatment, then a serious responsibility falls upon the physicians to recognize, and where necessary to prevent, the injurious alcohol consumption being caused perhaps partly by the substitution treatment itself. Further studies had to be conducted to prove the association between methadone or other substitutes and drinking alcohol, and to investigate how long patients can be treated with methadone before the risk of excessive alcohol consumption increases significantly. A previous study showed that $29 \%$ of the patients initially began to drink during the course of methadone maintenance treatment programs and that they are younger in comparison to nonopioid-addicted alcoholics [30]. Numerous studies continue to substantiate that patients during substitution treatment with methadone consume fewer illegal drugs, that the risk of HIV infection is reduced and that drugrelated crime rates fall [20,31-33]. DHC, which is frequently prescribed in Germany, appears to improve the addicts' situation just as well as methadone [16]. In all these studies, the illicit drug co-abuse but not alcohol was a target criterion. In a new study, it was reported that only one third of the patients in methadone maintenance treatment abstained from alcohol at the intake and follow-up [34]. It is known that with a lower dosage of methadone, co-abuse is higher [35]. Apparently, patients who discover they are hepatitis $\mathrm{C}$ positive, reduce their alcohol con- 
Table 3. Multiple logistic regression analyses: full model for the primary variables of interest and secondary potentially relevant variables

\begin{tabular}{|c|c|c|c|}
\hline \multirow[t]{2}{*}{ Variable } & \multicolumn{3}{|c|}{$\begin{array}{l}\text { Co-abuse of alcohol } \\
\text { (more than } 40 \mathrm{~g} \text { alcohol per day) }\end{array}$} \\
\hline & OR & $95 \% \mathrm{CI}$ & $\mathrm{p}$ \\
\hline \multicolumn{3}{|l|}{ Type of opioid dependency } & 0.0038 \\
\hline Methadone & 2.38 & $1.42-4.00$ & 0.0010 \\
\hline DHC & 1.67 & $1.12-2.49$ & 0.0124 \\
\hline Heroin & 1 & & \\
\hline \multicolumn{4}{|l|}{ Sex } \\
\hline Female & 0.61 & $0.44-0.84$ & 0.0025 \\
\hline Male & 1 & & \\
\hline \multicolumn{3}{|l|}{ Age } & 0.7734 \\
\hline$<23$ years & 0.71 & $0.27-1.82$ & 0.4715 \\
\hline $24-28$ years & 0.72 & $0.35-1.48$ & 0.3711 \\
\hline 29-34 years & 0.92 & $0.55-1.55$ & 0.7521 \\
\hline$>34$ years & 1 & & \\
\hline \multicolumn{3}{|l|}{ Duration of opioid use } & 0.0220 \\
\hline$<1$ year & 0.19 & $0.05-0.74$ & 0.0167 \\
\hline $2-5$ years & 0.81 & $0.35-1.88$ & 0.6253 \\
\hline $6-10$ years & 0.98 & $0.49-1.96$ & 0.9484 \\
\hline $11-15$ years & 1.36 & $0.76-2.46$ & 0.3022 \\
\hline$>15$ years & 1 & & \\
\hline \multicolumn{4}{|c|}{ Daily consumption of benzodiazepines } \\
\hline No & 0.52 & $0.38-0.71$ & 0.0000 \\
\hline Yes & 1 & & \\
\hline \multicolumn{4}{|c|}{ Daily consumption of barbiturates } \\
\hline No & 0.82 & $0.48-1.41$ & 0.4773 \\
\hline Yes & 1 & & \\
\hline \multicolumn{4}{|l|}{ Daily consumption of THC } \\
\hline No & 0.67 & $0.47-0.95$ & 0.0252 \\
\hline Yes & 1 & & \\
\hline
\end{tabular}

The variables 'marital status', 'history of imprisonment', history of emergency treatment', 'history of suicide attempts', 'employment', 'age at first opioid use' and 'daily consumption of cocaine' remained insignificant.

OR $=$ Odds ratio $95 \% \mathrm{CI}=95 \%$ confidence interval.

sumption considerably [28]. In principle it should be taken into consideration that in Germany alcohol is culturally accepted. Possibly the results would be somewhat different in a more abstinence-oriented culture.

Independently of the preferred daily opioid the following variables were associated with co-abuse of alcohol: (1) in the total population, males more often have an alcohol problem than females [36-38] - so it was not surprising that male opioid addicts more often had drunk alcohol daily than female opioid addicts; (2) that older patients, consuming drugs over a longer period, drink more alcohol seems realistic since the drug alone no longer appears to have the desired effect; (3) this would be an analogous explanation of the significantly higher benzodiazepine and cannabis consumption. Barbiturates are consumed (in total) in such small quantities that its use is difficult to assess with certainty. The subgroup of cocaine users is also so small that an assessment here appears to be of little practical value.

The multiple logistic regression analysis result proves that patients who have been treated with methadone or have taken DHC drink quite significantly more than patients who have injected heroin intravenously. To our knowledge this has not yet been described thus in any other literature. It is nevertheless necessary to consider that this concerns a retrospective study. Being male, additional consumption of benzodiazepines and THC was also confirmed as independent predictor for alcohol co-abuse. Increased age was not asserted as an independent predictor, but duration of drug use was. This may be explained by the fact that increased age implies a longer period of drug use, since drug addicts in this study on average first began injecting heroin at 20 years of age. In the first year of opioid consumption, it appeared that the opioid itself achieved the desired effect. Not quite every sixteenth patient drinks alcohol additionally. Already from the second year onward every fourth patient drinks alcohol daily. From the sixth to the tenth year, the proportion was $30 \%$, from the eleventh to the fifteenth year $40 \%$. The effect of the opioid itself no longer appears to be sufficient. With an opioid consumption of more than 15 years, slightly fewer patients drank alcohol daily $(32.4 \%)$. This is comparable to a British study in which a $32 \%$ harmful daily alcohol consumption has been diagnosed, where the average duration of opioid dependence was 17 years and the average age was 39 [28].

The results of this study suggest that co-abuse of alcohol should receive more attention in further studies of the effectiveness of substitution treatment programs with various substitution drugs. Particularly, a comparison between heroin and methadone should prove very interesting. More longitudinal studies are still needed.

\section{Acknowledgements}

This study was supported by the 'Modellprogramm Kompakttherapie im Verbund der Drogenhilfe 1990-1995' from the Department of Health of the Federal Republic of Germany. The authors would like to thank the staff of the detoxification unit 'villa' for their help with data collection and entry. 


\section{References}

1 Darke S, Ross J, Hall W: Overdose among heroin users in Sydney, Australia. I. Prevalence and correlates of non-fatal overdose. Addiction 1996;91:405-411.

2 Backmund M, Pfab R, Rupp P, Zilker T: Häufiger Notfall: Intoxikationen Suchtkranker durch Drogen und psychotrope Substanzen. Notarzt 1999;15:29-33.

3 Heckmann W, Püschel K, Schmoldt A, Schneider V, Schulz-Schaeffer W, Soellner R, Zenker H, Zenker J: Drogennotfallstudie; in Bundesministerium für Gesundheit (ed): Drogennot- und -todesfälle. Baden-Baden, Nomos, 1993, pp 132-149.

4 Cook S, Moeschler O, Michaud K, Yersin B: Acute opiate overdose: Characteristics of 190 consecutive cases. Addiction 1998;93:1559_ 1565.

5 Perret G, Deglon J-J, Kreek MJ, Ho A, La Harpe R: Lethal methadone intoxications in Geneva, Switzerland, from 1994 to 1998 . Addiction 2000;95:1647-1653.

6 Schmidt-Kittler A, von Meyer L: Drogenbedingte Todesfälle 1998. Suchtmedizin 2000;2: 103-109.

7 Grass H, Sticht G: Drogentod nach Haftentlassung - Untersuchung am Beispiel der Grossstadt Köln. Suchtmedizin 2001;3:97-100.

8 Gutjahr E, Gmel G, Rehm J: Relation between average alcohol consumption and disease: An overview. Eur Addict Res 2001;7:117-127.

9 Schuckit MA: Alkohol und Alkoholismus; in Braunwald E, Isselbacher KJ, Petersdorf RG, Wilson JD, Martin JB, Fauci AS (eds): Harrison's Principles of Internal Medicine. New York, McGraw-Hill, 1989, vol 2, pp 24802487.

10 Single E, Robson L, Rehm J, Xie X: Morbidity and mortality attributable to alcohol, tobacco, and illicit drug use in Canada. Am J Public Health 1999;89:385-390.

11 Gutjahr E, Gmel G, Rehm J: The relation between average alcohol consumption and disease: An overview. Eur Addict Res 2001;7: 117-121.

12 Strain EC, Stitzer ML, Liebson IA, Bigelow GE: Dose-response effects of methadone in the treatment of opioid dependence. Ann Intern Med 1993;119:23-27.

13 Goldstein A, Herrera J: Heroin addicts and methadone treatment in Albuquerque: A 22year follow-up. Drug Alcohol Depend 1995;40 139-150.
14 Strain EC, Bigelow GE, Liebson IA, Stitzer ML: Moderate- vs. high-dose methadone in the treatment of opioid dependence: A randomized trial. JAMA 1999;281:1000-1005.

15 Borg L, Broe DM, Ho A, Kreek MJ: Cocaine abuse sharply reduced in an effective methadone maintenance program. J Addict Dis 1999; 18:63-75.

16 Krausz M, Verthein U, Degkwitz P, Haasen C, Raschke P: Maintenance treatment of opiate addicts in Germany with medications containing codeine - Results of a follow-up study. Addiction 1998;93:1161-1167.

17 Hunt DE, Strug DL, Goldsmith DS, Lipton DS, Robertson K, Truitt L: Alcohol use and abuse: Heavy drinking among methadone clients. Am J Drug Alcohol Abuse 1986;12: 147-164.

18 Stastny D, Potter M: Alcohol abuse by patients undergoing methadone treatment programs. $\mathrm{Br}$ J Addict 1991;86:307-310.

19 Helander A, von Wachenfeldt J, Hiltunen A, Beck O, Liljeberg P, Borg S: Comparison of urinary 5-hydroxytryptophol, breath ethanol, and self-report for detection of recent alcohol use during outpatient treatment: A study on methadone patients. Drug Alcohol Depend 1999;56: 33-38.

20 Vogt M, Küfner H, Weiler D: Katamnestische Ergebnisse zur ambulanten medizinischen Rehabilitation unter Methadon-Substitution. Suchtmedizin 2000;2:93-102.

21 Soyka M: Die Alkoholkrankheit - Diagnose und Therapie. London, Chapman \& Hall, 1995.

22 Rehm J, Gmel G, Room R, Frick U: Average volume of alcohol consumption, drinking patterns and related burden of mortality in young people in established market economies of Europe. Eur Addict Res 2001;7:148-151.

23 Schmidt-Kittler H, von Meyer L: Drogenbedingte Todesfälle 1998. Suchtmedizin 2000;2: 103-109.

24 Backmund M, Meyer K, Eichenlaub D, Schütz CG: Predictors for completing an inpatient detoxification program among intravenous heroin users, methadone substituted and codeine substituted patients. Drug Alcohol Depend 2001;64:173-180.

25 Tuyns AJ, Pequignot G: Greater risk of ascitic cirrhosis in females in relation to alcohol consumption. Int J Epidemiol 1984;13:53-57.

26 Sorensen TIA, Bentsen KD, Eghoje K, Orholm M, Hobye G, Christoffersen PC: Prospective evaluation of alcohol abuse and alcoholic liver injury in men as predictors of development of cirrhosis. Lancet 1984;ii:241-244.
27 Green J, Jaffe JH, Carlisi JA, Zaks A: Alcohol use in the opiate use cycle of the heroin addict. Int J Addict 1978;13:1021-1033.

$28 \mathrm{McCusker} \mathrm{M}$ : Influence of hepatitis C status on alcohol consumption in opiate users in treatment. Addiction 2001;96:1007-1014.

29 Hulse GK, English DR, Milne E, Holman CDJ : The quantification of mortality resulting from the regular use of illicit opiates. Addiction 1999;94:221-229.

30 Gelb AM, Richman B, Anhand OP: Quantitative and temporal relationships of alcohol use in narcotic addicts and methadone maintenance patients undergoing alcohol detoxification. Am J Drug Alcohol Abuse 1978;5:191198

31 Dole VP, Nyswander ME: Medical treatmen for diacetylmorphine (heroin) addiction. JAMA 1965;193:646-650.

32 Grönbladh L, Öhlund LS, Gunne LM: Mortality in heroin addiction impact of methadone treatment. Acta Psychiatr Scand 1990;82:223227.

33 Metzger DS, Woody GE, McLellan AT, O'Brien CP, Druley P, Navaline H, DePhilippis D, Stolley $\mathrm{P}$, Abrutyn E: Human immunodeficiency virus seroconversion among intravenous drug users in and out of treatment: An 18 month prospective follow-up. J Acquir Immune Defic Syndr 1993;6:1049-1055.

34 Gossop M, Marsden J, Stewart D, Rolfe A: Patterns of drinking and drinking outcomes among drug misusers: 1-year follow-up results. J Subst Abuse Treat 2000;19:45-50.

35 Johnson RE, Chutuape MA, Strain EC, Walsh SL, Stitzer ML, Bigelow GE: A comparison of levomethadyl acetate, buprenorphine, and methadone for opioid dependence. N Engl J Med 2000;343:1290-1297.

36 Myers JK, Weissmann MM, Tischler GL Holzer CE, Leaf PJ, Orvaschel H, Anthony JC, Boyd JH, Burke JD, Kramer M, et al: Sixmonth prevalence of psychiatric disorders in three communities 1980 to 1982 . Arch Gen Psychiatry 1984;41:959-967.

37 Regier DA, Boyd JH, Burke JD, Rae DS, Myers JK, Kramer M, Robins LN, Lin KG, Karno M, Locke BZ: One-month prevalence of mental disorders in the United States. Arch Gen Psychiatry 1988;45:977-986.

38 Fichter M: Verlauf psychischer Erkrankungen in der Bevölkerung. Berlin, Springer, 1990 